\title{
Moisture Safety of Wooden Buildings - Design, Construction and Operation
}

\section{Kristina Mjörnell*}

RISE Research Institutes of Sweden, Eklandagatan 86, 41266 Gothenburg, Sweden

Division of Building Physics, Lund University, Box 118, 22100 Lund, Sweden

\section{Lars Olsson}

RISE Research Institutes of Sweden, Eklandagatan 86, 41266 Gothenburg, Sweden

*Corresponding author: kristina.mjornell@ri.se

Гrossef http://dx.doi.org/10.5755/j01.sace.24.1.22341

During the last decade, building in wood has increased, mainly due to environmental awareness and targets to decrease the carbon footprint originated from the production of building materials. New technologies such as CLT (cross laminated timber) have accelerated the construction of multi-story wooden buildings. The CLT structure has been used both for housing and offices. Due to the extensive size of the buildings and relatively fast assembly of the buildings, weather protection has not always been used. It is commonly known that building materials sensitive to moisture need to be protected against high moisture conditions and water during construction. If this is not done, there is an increased risk of microbial growth which can result in health problems for future users of the building, extensive costs for the remediation and exchange of materials, but also lack of trust in the construction industry. There are disagreements between the building industry and researchers how sensitive wooden buildings are to exposure to high moisture levels and water during storage at sites and construction. Based on results from several research projects studying moisture conditions both in the laboratory and in the field, recommendations for procurement, storage and handling of wood during construction to assure moisture safety are suggested in this paper.

Keywords: CLT, guidance, massive wooden buildings, moisture safety, mould growth.

The Nordic countries have a long tradition to build in wood. Wood is suitable for construction of buildings since it is a common, inexpensive, durable material with a long lifetime, if not exposed to extreme conditions. During the last decades many Swedish municipalities have shown increased interest in building in wood to strive towards ambitious environmental targets considering low carbon footprint housing. This has led to many national initiatives promoting wood for new urban developments, (Trästad 2018) and (Smart Housing Småland 2018).

Due to the increased interest for wooden buildings by the market, new technologies based on cross-laminated timber (CLT) which gives a higher rigidity and strength to wooden structures have been developed, enabling the evolution of high-rise buildings. CLT panels are laminated wood products and systems based on prefabricated elements made of 3-7 perpendicular oriented layers of parallel boards glued together (Trästad 2018). The advantages of building with CLT are

\section{Introduction}

Moisture Safety of Wooden Buildings Design, Construction and Operation

Received 2018/12/16

Accepted after revision 2019/02/05 
many from a lifecycle perspective, partly because of the low environmental impact (embodied energy), prefabrication, which means efficient production which reduces construction time, but also providing a better working environment and minimizing waste. The construction and technology are imported from Central Europe. Lately, a lot of attention has been paid to moisture issues, especially when CLT buildings are erected without weather protection. The suppliers claim that weather protection is not necessary, whereas the researchers fear that exposure to rain during erection might cause damages and problems with mould growth in the future. In some cases, it is practically impossible to arrange weather protection since the width and height of the construction would require very complicated fasteners to cope with the wind loads from the tent, Fig. 1-3.

Many buildings in Sweden, both new and old, suffer from moisture-related problems causing both decreased durability and mould growth which may affect the indoor air quality with negative consequences on health. The National board of housing, building and planning in Sweden carried out

Fig. 1

Examples of moisture critical construction methods

are multi-storey buildings constructed

without weather protection and storing wood and insulation material wrapped in plastic sheeting at the building site

Fig. 2

The left building is a multi-story wooden building assembled without weather protection and the right is a multi-storey building assembled with weather protection
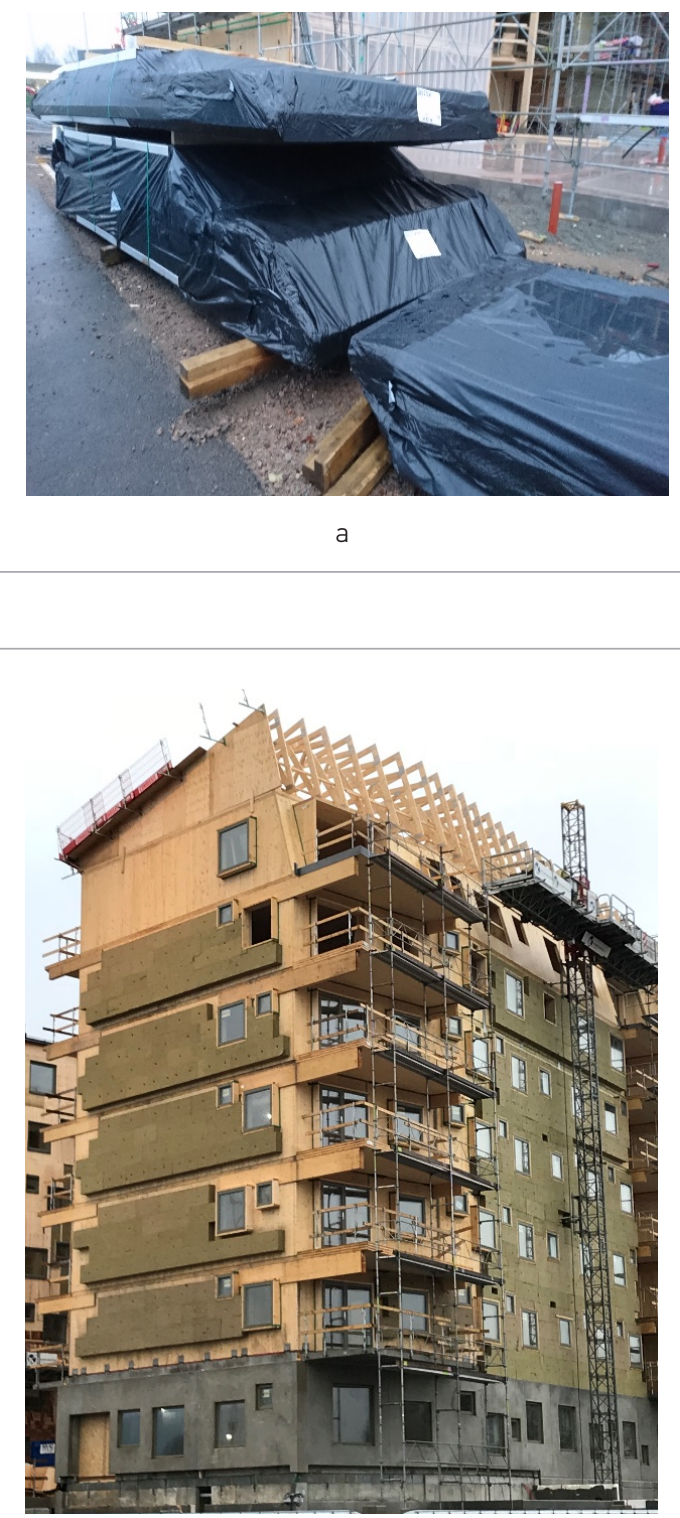

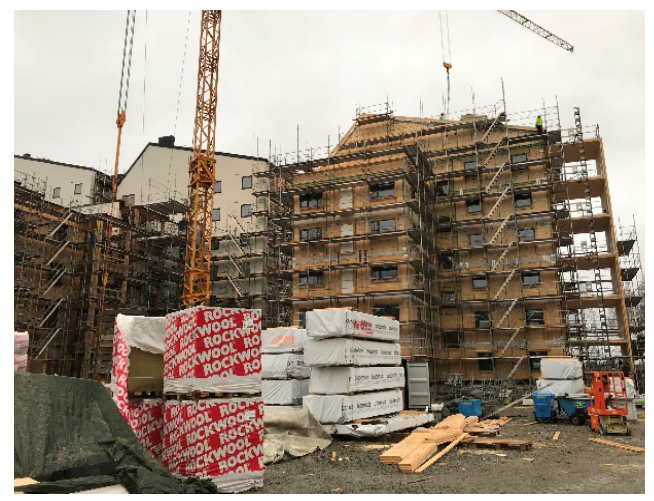

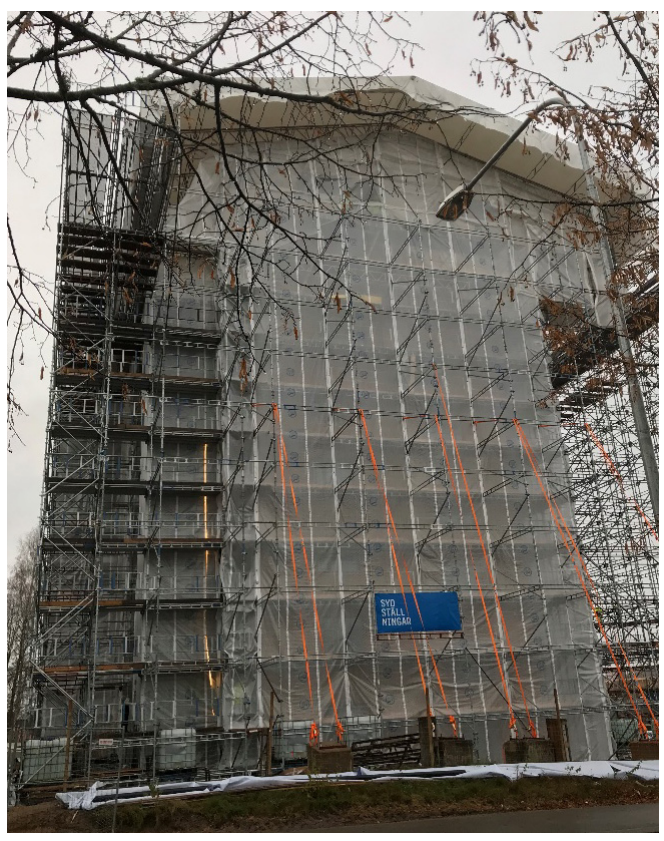

b 


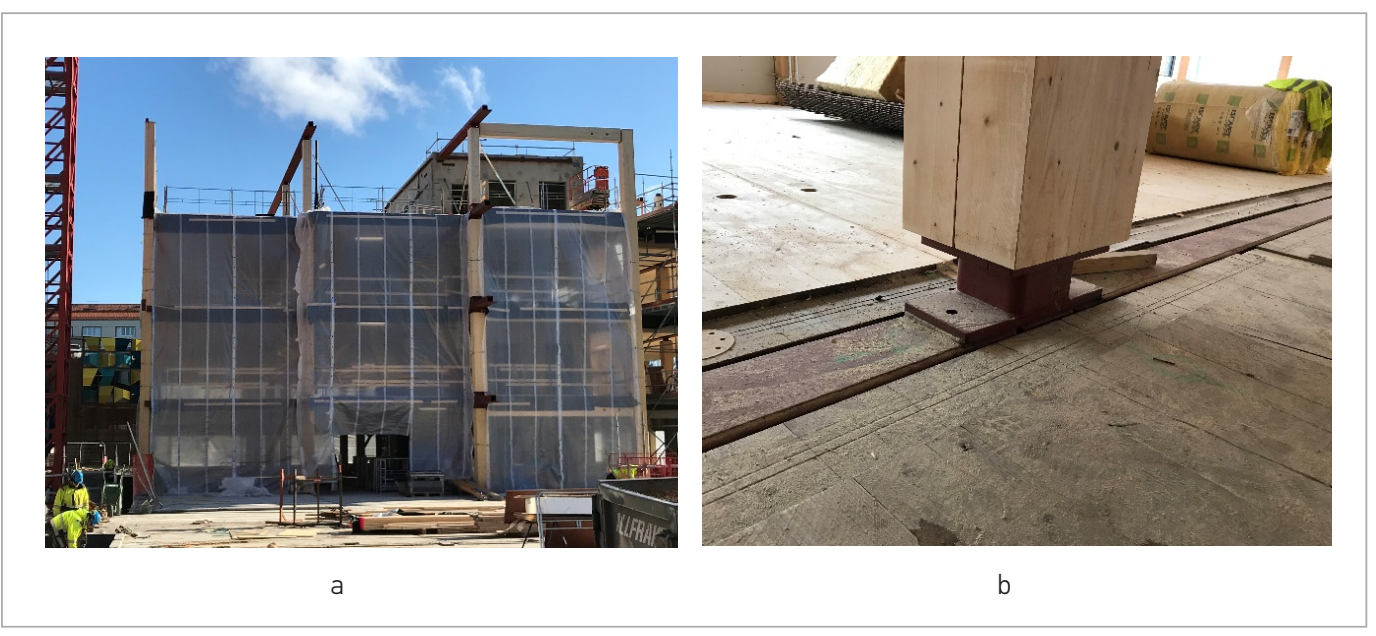

Fig. 3

New office building with CLT (crosslaminated timber) framework assembled without weather protection

a nationwide study of buildings' energy use, technical status and indoor environment, named the BETSI study. The material is unique, as it is based on investigations of a stochastic selection of 1800 buildings (Boverket 2009). The estimation was that approximately 66 per cent of all buildings in Sweden had some type of damage and 45 percentage of these damages were caused by moisture, which could have an impact on the indoor environment. However, most shortcomings that were registered were not of a serious nature. The cost for remedying all identified damage and meeting needs for maintenance was estimated to between 230 and 330 billion SEK (approximately 23-33 Billion Euros), also including measures for decreasing noise levels in schools. In addition to high costs for remediation, the customers, tenants and users of the buildings lose confidence in the building industry when their buildings are exposed to moisture problems. These problems could have been avoided if moisture issues had been focused on and dealt with throughout the building process.

A method for including moisture safety in the building process (ByggaF) was developed ten years ago and is referred to in the Swedish building regulation BBR and is quite widely used in the Swedish building sector. The purpose of the method is to help all the stakeholders involved to work with moisture safety activities and to document them in a structured way. The method includes a number of routines, templates and checklists for clients to formulate requirements for moisture safety and to follow up and document the measures carried out by different participants. There are also tools for architects and design engineers, such as lists of references to literature, checklists and design examples to use for moisture safety design. For contractors, specific routines have been developed for moisture control during construction. The method has been applied to several building projects. Based on the experience from these projects, the method and the tools have been evaluated and revised, (Mjörnell et al 2012, ByggaF 2018). ByggaF gives guidance on a very general level and does not provide advice on choice of design of constructions and materials or how to handle wood at the construction site. Thus, a specific guide for controlling moisture and mould in wooden constructions exposed to the outdoor climate is needed. A guide with recommendations, based on former research studies performed by the authors, is presented in this paper.

\section{Methods used to investigate moisture condition in Swedish wooden buildings}

A few years ago, there were two large national research initiatives on durability in wooden buildings "Future Wooden Buildings" and "WoodBuild". The outcome of these projects was presented in a number of scientific publications but also as recommendations to the national building industry in Sweden. (Mundt-Petersen 2013, Johansson 2014, Olsson 2014). 
As part of the program, a number of field studies were made in order to increase knowledge on the hygro-thermal conditions that wooden buildings are exposed to during their lifetime including both construction and operation phase. Moisture and temperature conditions in wood were investigated in 24 prefabricated detached houses, three wooden house factories and two apartment buildings, (Olsson 2014). Wooden sills frequently become wet due to rain during construction. There was however a disagreement between the wooden house industry and the researchers how much water is absorbed and how fast the moisture is drying out. Therefore, a laboratory study was designed in order to examine whether wooden sills and wooden studs can withstand short-term exposure to free water, before or after the wall design is closed up with tight layers, and whether there is any risk of mould growth, (Olsson and Mjörnell 2012).

Moisture is not only a problem during the erection of wooden buildings but also during the use phase. During the last few decades well-insulated, rendered, unventilated and undrained stud walls have been very popular in Sweden. Unfortunately, this structure has shown to be sensitive to moisture, especially driving rain. Experience from surveys of more than a hundred buildings shows that the problem is that moisture enters the structure - for example, at joints, poor connections to windows and doors, or at fixing studs - wetting the materials inside the stud wall and causing mould growth. The damage is never visible on the surface of the wall but is hidden within the wall. The only way to detect the damage is to measure the moisture conditions inside the wall. A national survey was carried out in order to determine the extent of the problem and any connection to local climates, orientation, frequency and direction of driving rain, design of connections, type of plaster (thin or thick), and insulation material (mineral wool or cellular plastic) etc. (Samuelsson et al 2008).

In addition to that, a number of mock-ups of rendered stud walls of existing and new designs have been tested in the laboratory, complemented by theoretical investigations of heat and moisture conditions in the walls. Complementary laboratory studies have been carried out to study how the water droplets enter different types of holes and slits and how different conditions such as pressure difference, the shape of the opening, surface material and dams affect the leakage. (Olsson 2018a, Olsson 2018b).

\section{Results Results from former research studies on moisture conditions in Swedish wooden buildings}

The results from one of the investigations consist of data on exposure climates during the construction process, moisture ratios in wood and microbiological analyses of wood at all stages from storage at the factory until assembly at site. The conclusion from the study was that climatic conditions to which wood is normally exposed during the construction stage do not seem to contribute to the growth of mould, provided that the wood has not been exposed to free water or has been kept under damp conditions for longer periods of time at favourable temperatures. In this study, microbial growth was found on almost one-third of all the samples taken and elevated and high moisture ratios were found in one-third of all the samples. Since the exposure conditions depend to a very large extent on the weather conditions while the building is being erected and before it is weatherproof, the results also seem to indicate that wood can have collected microbial growths before it has reached the manufacturer's stores or production in the factory. The results of the field measurements at the building sites show that, regardless of the particular manufacturer, the most moisture-exposed and, at the same time, probably the most critical, part of the structure is generally the bottom edge of the outer wall and the sill. The risk of materials being damp, and of microbial growth, can however be reduced by appropriate changes to the method of erection and modifications of the design, or by better weather protection or coverage at the site (Olsson et al 2011). 
The results from the laboratory study on wooden stud walls show that all sill designs tested in the study were damaged by extensive mould growth if they were subjected to water for as short a time as one or three days. Mould growth occurred mainly on the material surfaces facing the direction in which drying-out was impeded by the moisture barrier, steel plates or other materials that were damp or impermeable to water vapour. The drying time for sills was at least three to six weeks, depending on the design. Many surfaces had no visible mould growth, but when examined under a microscope, the mould growth was extensive. This strengthens the view that microbial analyses are necessary in order to safely determine whether the wood is contaminated by mould. (Olsson and Mjörnell 2012). The results from this study form the basis for the guidelines for the construction industry on how to design, use, and handle wood in exterior wall designs presented in this paper.

\section{Recommendations based on research on moisture conditions in Swedish wooden buildings}

In case unforeseen wetting or moistening occur: If there is any suspicion that wood or wooden constructions have been exposed for prolonged moistening or high relative humidity in the surrounding air, a microbiological analysis is needed, or the material needs to be substituted or planed. If the wood or wooden structure has been exposed to short-term shallow moistening caused by precipitation or other water, the moist surfaces of the wood should be dried out immediately, within one day, and be checked by moisture content measurements. If still moist, drying should continue followed by a microbiological analysis. An alternative measure could be to substitute the material or plane away affected parts. If the wood or wooden structure has been exposed for short-term but deep or long-term moistening (several days) precipitation or other water, the wood should be dried out and the drying process should be checked by measuring the moisture content. After finished drying, a microbiological analysis should be made to ensure that there is no presence of microbiological growth. Alternatively, the wood should be substituted, or the surface should be planed.

By the time the house is tight, and the surfaces are not in direct contact with outdoor air the following should be applied: The climate should be controlled. The moisture content in the indoor air should be restricted and additional moisture should be prevented by for example ventilation or dehumidification. Continuous monitoring of relative humidity and temperature is needed to control the amount of additional moisture and assure a sufficiently dry drying climate. Heating usually speeds up the evaporation of moisture from materials and could be a prerequisite for reducing the drying time in order to keep the time plan of construction. Increased temperature often leads to an increased moisture content in the air and risk of condensation or high moisture levels at cold surfaces or in air-leaky structures. Good air-tightness is needed to avoid moist air to penetrate through the wooden structure.

Perform moisture rounds at the building site, at least ones a week, proposed according to the routine in ByggaF (ByggaF 2018).

The main problem with wood as a construction material is that it is sensitive to moisture and water causing mould and in several cases rot damages, as well as insect pests, which might cause indoor air problems but also structural failures shortening the lifetime of the building. During the construction phase, there is a high risk of microbiological growth if the wood is exposed to water. If the wood has been exposed to water or high moisture levels there the margins are small before mould starts to grow. At favourable conditions such as high temperatures and humidity, which is common during summertime, mould growth may start within a few weeks but if the wood gets wet, mould growth may occur within a few days. There are also risks for cracks due to shrinking when the wood dries, which may affect tight layers in the house. At low temperatures, the mould growth is slower but on the other hand, the drying out takes much longer time. Also, well-insu-

\section{Discussion}


lated buildings have a lower drying out potential than poorly insulated buildings. Drying of wood is quite slow, especially if the water has been sucked into joints or connections between wood and other materials. There is a disagreement in the construction sector whether it is necessary to use weather protection when assembling wooden buildings. On the other hand, there is no doubt that wood must be protected from moisture and water. To neglect wetting or moistening of wood during construction could imply costs for repairing damages which must be calculated for. Such damages also involve an increased cost for investigation, microbiological analyses, drying out, decontamination of surfaces or substitution of materials. If weather protection is not used, extensive control of moisture conditions and microbiological growth on wood constructions is needed to assure moisture safety throughout the construction time. The risk of damages can be reduced by using weather protection.

\section{Conclusions}

During the last decades, many Swedish municipalities have required building in wood to meet the ambitious environmental targets involving decreasing the carbon footprint. The advantages of wood construction may be jeopardized if subjected to discussions about moisture risks and increased costs and environmental impact due to a replacement of material in case of damages. The best strategy to assure a moisture safe construction is to make sure that wood is not exposed to water or long periods of high relative humidity, which means that moisture safe, robust structures, weather protection and moisture safe construction methods must be used. To neglect moisture safety could imply a high risk of damage with extensive costs for investigations, decontamination or substitution of material, and time delays as consequences.

\section{Acknow- ledgment}

The research which forms the basis of the recommendations presented in this paper was carried out within the research programs "Framtidens Trähus" (Future wooden buildings) and "WoodBuild" founded by VINNOVA, Sweden's Innovation Agency.

\section{References}

Boverket (2009). Så mår våra hus - Redovisning av regeringsuppdrag beträffande byggnaders tekniska utformning m. m. ISBN pdf: 978-91-86342-29-6.

ByggaF (2018). Method for moisture safety in the building process. http://www.fuktcentrum.lth.se/ verktyg-och-hjaelpmedel/fuktsaekert-byggande/ byggaf-metoden/ Access date 2018-12-18.

Früwald-Hansson, E., Bardage, S. and Thelandersson, S. (2013) Modelling the risk for mould growth on timber stored outdoors protected from rain. Proceedings of 44th IRG annual meeting in Stockholm, IRG/WP 13-20529.

Johansson, P. (2014). Determination of the Critical Moisture Level for Mould Growth on Building Materials, Rapport TVBH-1020 Lund 2014. https://lup.lub.lu.se/ search/publication/72d4403b-3b90-4c71-9aee-8aa8dbebc79e

Mjörnell, K., Arfvidsson, J., \& Sikander, E. (2012). A Method for Including Moisture Safety in the Building Process. Indoor and Built Environment, 21(4), 583594. https://doi.org/10.1177/1420326X11428340

Mundt-Petersen S. O. (2013) Moisture Safety in Wood Frame Walls - Blind evaluation of the hygro- thermal calculation tool WUFI 5.0 using field measurements and determination of factors affecting the moisture safety. TVBH-3059.

Olsson, L. Mjörnell, K. Johansson, P. (2011). Moisture and mould in prefabricated timber frame constructions during production until enclosure of the house: Proceedings of the 9th Nordic Symposium on Building Physics (NSB 2011), Tampere, Finland, May 29-June 2, 2011, pp. 339-346.

Olsson, L., Mjörnell, K. (2012). Laboratory investigation of sills and studs exposed to rain, Proceedings of the 5th IBPC, Kyoto, Japan, May 28-31, 2012.

Olsson, L. (2014). Moisture Conditions in Exterior Wooden Walls and Timber During Production and Use. Licentiate thesis 2014:2 Chalmers University of Technology. ISBN no. 1652-9146.

Olsson, L. (2018a). Rain resistance of façades with façade details: A summary of three field and laboratory studies. Journal of Building Physics, 41 (6), 521 532. https://doi.org/10.1177/1744259117713265

Olsson, L. (2018b). Driving Rain Tightness, Intrusion rates and Phenomenology of Leakages in Defects of facades: A New Calculation Algorithm. PhD The- 
sis. Chalmers University of Technology. ISBN: 97891-7597-813-0.

Smart housing Småland (2018). http://smarthousing.nu/en/ Access date 2018-12-17.

Samuelson, I., Mjörnell, K., Jansson, A. (2008). Moisture damage in rendered, undrained, well insulated stud walls. Proceedings of the 8th Symposium on Building Physics in the Nordic Countries, vol. 3, p 1253-1260. Copenhagen, Denmark SS-EN 12865. Thelandersson, S., Isaksson, T. (2013) Mould resistance design (MRD) model for evaluation of microbiological growth under varying climate conditions. Building Environment (65), pp 18-25. https://doi. org/10.1016/j.buildenv.2013.03.016

Trästad 2012, Wood City Sweden (2018). http:// www.trastad.se/english/ access date 2018-12-17.

\section{KRISTINA MJÖRNELL}

VP Business- and innovation area Sustainable cities and communities

RISE Research institutes of Sweden

\section{Adjunct professor}

Division of Building Physics at Lund University

\section{Main research area}

Moisture safety, energy efficient buildings, sustainable renovation

\section{Address}

Eklandagatan 86, 41266 Gothenburg

Tel. +46730885745

E-mail: kristina.mjornell@ri.se

\section{LARS OLSSON}

Senior researcher

RISE Research Institutes of Sweden

\section{Main research area}

Moisture safety, rain intrusion, facades, wooden structures, quality assurance

\section{Address}

Box 857, 50115 Borås, Sweden

Tel. +46705850908

E-mail: lars.olsson@ri.se

\section{About the Authors}

